\title{
Effect of Albuterol on Expiratory Resistance in Mechanically Ventilated Patients
}

\author{
Eumorfia Kondili MD, Christina Alexopoulou MD, George Prinianakis MD, \\ Nektaria Xirouchaki MD, Katerina Vaporidi MD, and Dimitris Georgopoulos MD
}

\begin{abstract}
BACKGROUND: In mechanically ventilated patients with COPD, the response of the expiratory resistance of the respiratory system (expiratory $R_{R S}$ ) to bronchodilators is virtually unknown. OBJECTIVE: To examine the effect of inhaled albuterol on expiratory $R_{R S}$, and the correlation of albuterol-induced changes in expiratory $R_{R S}$ with end-inspiratory resistance and the expiratory flow-volume relationship. METHODS: We studied 10 mechanically ventilated patients with COPD exacerbation, before and $30 \mathrm{~min}$ after administration of albuterol. We obtained flow-volume curves during passive expiration, divided the expired volume into 5 equal volume slices, and then calculated the time constant and dynamic effective deflation compliance of the respiratory system (effective deflation $C_{R S}$ ) of each slice via regression analysis of the volume-flow and post-occlusion volume-tracheal pressure relationships, respectively. For each slice we calculated expiratory $R_{R S}$ as the time constant divided by the effective deflation $\mathrm{C}_{\mathrm{RS}}$. RESULTS: Albuterol significantly decreased the expiratory $R_{R S}$ (mean expiratory $R_{R S} 42.68 \pm 17.8 \mathrm{~cm} \mathrm{H} \mathrm{H}_{2} \mathrm{O} / \mathrm{L} / \mathrm{s}$ vs $38.08 \pm 16.1 \mathrm{~cm} \mathrm{H} \mathrm{H}_{2} \mathrm{O} /$ $\mathrm{L} / \mathrm{s}$ ) and increased the rate of lung emptying toward the end of expiration (mean time constant $2.51 \pm 1.2 \mathrm{~s}$ vs $2.21 \pm 1.2 \mathrm{~s}$ ). No correlation was found between the albuterol-induced changes in expiratory $R_{R S}$ and that of end-inspiratory resistance. Only at the end of expiration did albuterolinduced changes in the expiratory flow-volume relationship correlate with changes in expiratory $\mathbf{R}_{\mathrm{RS}}$ in all patients. CONCLUSIONS: In patients with COPD, albuterol significantly decreases expiratory resistance at the end of expiration. In mechanically ventilated patients, neither inspiratory resistance nor the whole expiratory flow-volume curve may be used to evaluate the bronchodilator response of expiratory resistance. Key words: COPD; expiratory resistance; mechanical ventilation; bronchodilators; albuterol. [Respir Care 2011;56(5):626-632. (C) 2011 Daedalus Enterprises]
\end{abstract}

\section{Introduction}

Bronchodilators have a central role in the treatment of obstructive lung disease and COPD exacerbation; they aim

Eumorfia Kondili MD, Christina Alexopoulou MD, George Prinianakis MD, Nektaria Xirouchaki MD, Katerina Vaporidi MD, and Dimitris Georgopoulos MD are affilated with the Department of Intensive Care Medicine, University Hospital of Heraklion, University of Crete, Heraklion, Crete, Greece.

The authors have disclosed no conflicts of interest.

Correspondence: Eumorfia Kondili MD, Department of Intensive Care Medicine, University Hospital of Heraklion, Heraklion, Crete, Greece 71110. E-mail: konde@med.uoc.gr.

DOI: $10.4187 /$ respcare.00984 to decrease the resistance to expiratory flow. ${ }^{1}$ The effect of bronchodilators in mechanically ventilated patients is commonly evaluated by the decrease in end-inspiratory airway resistance and in intrinsic PEEP. ${ }^{2-4}$ End-inspiratory airway resistance and intrinsic PEEP are easily measured at the bedside in ventilated patients, without spontaneous respiratory efforts, with end-inspiratory and end-expiratory occlusions. ${ }^{5}$ It is important to recognize however, that inspiratory and expiratory resistance differ, and it is the expiratory resistance that affects the development of dynamic hyperinflation. Therefore, bronchodilator therapy in mechanically ventilated patients would ideally be evaluated based on the decrease in expiratory resistance.

Recently we described a new technique to estimate the expiratory resistance of the respiratory system $\left(\mathrm{R}_{\mathrm{RS}}\right)$ in the presence of flow limitation. ${ }^{6,7}$ The present physiology study evaluates the effect of inhaled albuterol on expiratory re- 
sistance in patients with COPD exacerbation, and examines the correlation of albuterol-induced changes in expiratory and inspiratory resistance.

\section{Methods}

Our institutional ethics committee approved this study, and informed consent was obtained from each patient's surrogate. We studied 10 patients on mechanical ventilation for acute respiratory failure due to COPD exacerbation. In all but one patient the exacerbation was attributed to infection. The inclusion criteria were an established diagnosis of $\mathrm{COPD}^{1}$ and hemodynamic stability in the preceding 24 hours. The exclusion criteria were the presence of a chest tube and a persistent air leak, and hemodynamic instability. All patients were sedated with a continuous infusion of propofol $(3-5 \mathrm{mg} / \mathrm{kg} / \mathrm{h})$ and fentanyl $(2.5 \mu \mathrm{g} / \mathrm{kg} / \mathrm{h})$, and had a Ramsay sedation scale score of 6 . All patients were ventilated (840, Puritan-Bennett, Carlsbad, California, or Evita 2, Dräger, Lübeck, Germany) on a volume control mode, without spontaneous respiratory efforts, with a constant inspiratory flow rate; and with respiratory rate, inspiratory time, and tidal volume determined by the primary physician. Absence of respiratory muscle activity was based on absence of negative deflection of airway pressure, stabilization of the airway pressure waveform, constancy of peak inspiratory pressure from breath to breath, and exponential decline of expiratory flow. In patients in whom respiratory muscle activity was not inhibited, a neuromuscular blocking agent was administered (atracurium $25 \mathrm{mg}$ ).

We inserted a manually operated pneumatic occlusion valve (9300, Hans-Rudolf, Shawnee, Kansas) between the endotracheal tube and the ventilator Y-piece. We measured flow, volume, airway pressure, and tracheal pressure at the airway opening, as previously described. ${ }^{6,7}$ All inhaled bronchodilators were withheld for 6 hours before the study period. PEEP was zero during the study period. The protocol for the evaluation of expiratory resistance and flow limitation includes 3 steps, previously described.6,7 The airway is occluded at end-inspiration for $3 \mathrm{~s}$ (with the end-inspiratory hold button on the ventilator), then:

Step 1: The patient is permitted to exhale to end-expiratory lung volume, determined by ventilator frequency and tidal volume.

Step 2: Passive expiration is performed directly to the atmosphere by removing the expiratory ventilator circuit during the preceding end-inspiratory occlusion, until expiratory flow is zero.

Step 3: We perform one approximately 3-second airway occlusion per breath, with the pneumatic occlusion valve, at different (random) points during expiration. In each patient we conduct expiratory airway occlusion in at least 20 breaths, to obtain data throughout expiration.
We also measure the end-inspiratory $\mathrm{R}_{\mathrm{RS}}$ with the occlusion technique. Minimum and maximum inspiratory $R_{R S}$ were computed according to standard formulas and procedures. ${ }^{5}$ We also calculated the difference between the maximum and minimum inspiratory $\mathrm{R}_{\mathrm{RS}}\left(\Delta \mathrm{R}_{\mathrm{RS}}\right)$. We measured intrinsic PEEP via end-expiratory occlusion, with the appropriate button on the ventilator.

The bronchodilator consisted of 4 puffs of albuterol (100 $\mu \mathrm{g} /$ puff, Aerolin, Glaxo Wellcome) administered via metered-dose inhaler with spacer (ACE, Diemolding Healthcare, Canastota, New York) as previously described. ${ }^{4}$ Thirty minutes after albuterol administration, the whole procedure and measurements were repeated.

\section{Assessment of Flow Limitation}

For a given experimental condition, we obtained an expiratory flow-volume curve without (step 1) and with (step 2) decreasing the downstream pressure. We assessed flow limitation by comparing the expiratory flows at a given portion of lung volume, as previously described.6,7

\section{Determination of the Pattern of Lung Emptying}

The pattern of emptying was assessed as previously described.6,7 At each experimental condition we plotted

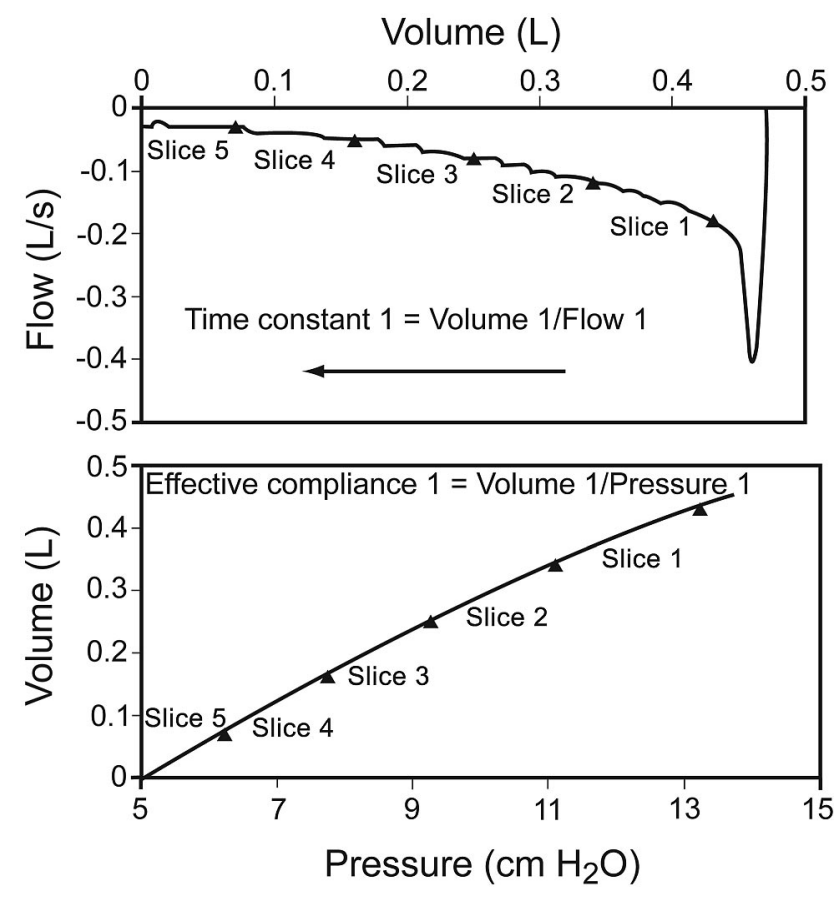

Fig. 1. Flow-volume and post-occlusion tracheal pressure-volume curves during passive expiration in a representative patient. We divide the curves into 5 equal slices. The long arrow indicates the direction of expiration. The time constant and dynamic effective compliance of slice 1 is obtained by analyzing the flow-volume and pressure-volume relationships of the data from that slice. 


\section{Effect of Albuterol on Expiratory Resistance in Mechanically Ventilated Patients}

Table 1. Baseline Characteristics

\begin{tabular}{|c|c|c|c|c|c|c|c|c|c|c|}
\hline $\begin{array}{l}\text { Patient } \\
\text { Number }\end{array}$ & Sex & $\begin{array}{l}\text { Age } \\
\text { (y) }\end{array}$ & $\begin{array}{c}\text { Mechanical } \\
\text { Ventilation } \\
\text { Days }\end{array}$ & $\begin{array}{l}\text { Tidal Volume } \\
\text { (mL/kg IBW) }\end{array}$ & $\begin{array}{l}\text { Respiratory Rate } \\
\text { (breaths/min) }\end{array}$ & $\begin{array}{c}\text { Inspiratory/ } \\
\text { Expiratory } \\
\text { Ratio }\end{array}$ & $\mathrm{F}_{\mathrm{IO}_{2}}$ & $\mathrm{pH}$ & $\begin{array}{c}\mathrm{P}_{\mathrm{O}_{2}} \\
(\mathrm{~mm} \mathrm{Hg})\end{array}$ & $\begin{array}{c}\mathrm{P}_{\mathrm{aCO}} \\
(\mathrm{mm} \mathrm{Hg})\end{array}$ \\
\hline 1 & M & 74 & 3 & 6.4 & 18 & 0.33 & 0.30 & 7.4 & 80 & 53 \\
\hline 2. & M & 66 & 4 & 6.4 & 14 & 0.25 & 0.50 & 7.35 & 70 & 60 \\
\hline 3 & M & 69 & 5 & 6.3 & 16 & 0.33 & 0.35 & 7.50 & 82 & 50 \\
\hline 4 & M & 67 & 3 & 6.1 & 16 & 0.33 & 0.35 & 7.36 & 64 & 66 \\
\hline 5 & M & 66 & 4 & 6.7 & 16 & 0.33 & 0.35 & 7.41 & 81 & 65 \\
\hline 6 & M & 65 & 6 & 6.6 & 15 & 0.25 & 0.40 & 7.43 & 79 & 50 \\
\hline 7 & M & 78 & 8 & 6.4 & 14 & 0.33 & 0.40 & 7.42 & 67 & 54 \\
\hline 8 & M & 70 & 5 & 6.0 & 16 & 0.25 & 0.45 & 7.38 & 84 & 76 \\
\hline 9 & $\mathrm{~F}$ & 72 & 6 & 5.6 & 18 & 0.33 & 0.35 & 7.49 & 57 & 83 \\
\hline 10 & M & 70 & 4 & 4.3 & 16 & 0.25 & 0.50 & 7.34 & 76 & 72 \\
\hline \multicolumn{2}{|c|}{ Mean \pm SD } & $69.7 \pm 4.1$ & $4.8 \pm 1.5$ & $6.08 \pm 0.70$ & $15.9 \pm 1.37$ & $0.30 \pm 0.04$ & $0.37 \pm 0.07$ & $7.4 \pm 0.05$ & $74 \pm 9$ & $63 \pm 12$ \\
\hline
\end{tabular}

Table 2. Effect of Salbutamol on $\mathrm{P}_{\text {plat }}$, Intrinsic PEEP, and End-Tidal Trapped Volume

\begin{tabular}{|c|c|c|c|c|c|c|}
\hline \multirow[b]{2}{*}{$\begin{array}{l}\text { Patient } \\
\text { Number }\end{array}$} & \multicolumn{3}{|c|}{ Before Salbutamol } & \multicolumn{3}{|c|}{ After Salbutamol } \\
\hline & $\begin{array}{c}\mathrm{P}_{\text {plat }} \\
\left(\mathrm{cm} \mathrm{H}_{2} \mathrm{O}\right)\end{array}$ & $\begin{array}{l}\text { Intrinsic PEEP } \\
\left(\mathrm{cm} \mathrm{H}_{2} \mathrm{O}\right)\end{array}$ & $\begin{array}{c}\text { End-Tidal Trapped } \\
\text { Volume (L) }\end{array}$ & $\begin{array}{c}\mathrm{P}_{\text {plat }} \\
\left(\mathrm{cm} \mathrm{H}_{2} \mathrm{O}\right)\end{array}$ & $\begin{array}{c}\text { Intrinsic PEEP } \\
\left(\mathrm{cm} \mathrm{H}_{2} \mathrm{O}\right)\end{array}$ & $\begin{array}{c}\text { End-Tidal Trapped } \\
\text { Volume (L) }\end{array}$ \\
\hline 1 & 12.0 & 5.7 & 0.83 & 11.9 & 5.1 & 0.59 \\
\hline 2 & 13.6 & 5.2 & 0.23 & 13.3 & 3.8 & 0.13 \\
\hline 3 & 13.3 & 5.9 & 0.12 & 13.0 & 3.1 & 0.14 \\
\hline 4 & 14.0 & 6.0 & 0.87 & 14.8 & 6.9 & 0.69 \\
\hline 5 & 13.0 & 6.5 & 0.88 & 12.9 & 6.5 & 0.69 \\
\hline 6 & 12.5 & 5.3 & 0.47 & 10.7 & 3.1 & 0.35 \\
\hline 7 & 18.1 & 11.7 & 0.84 & 16.1 & 9.2 & 0.54 \\
\hline 8 & 22.8 & 16.1 & 0.22 & 21.9 & 13.8 & 0.17 \\
\hline 9 & 20.6 & 7.9 & 0.13 & 19.3 & 6.5 & 0.17 \\
\hline 10 & 22.6 & 14.0 & 0.40 & 18.7 & 10.8 & 0.47 \\
\hline Mean $\pm \mathrm{SD}$ & $16.2 \pm 4.3$ & $8.4 \pm 4.0$ & $0.50 \pm 0.33$ & $\begin{array}{l}15.3 \pm 3.7 \\
(P=.04)\end{array}$ & $\begin{array}{c}6.9 \pm 3.5 \\
(P=.004)\end{array}$ & $\begin{array}{c}0.39 \pm 0.23 \\
(P=.03)\end{array}$ \\
\hline
\end{tabular}

$\overline{\mathrm{P}_{\text {plat }}=\text { static end-inspiratory plateau pressure }}$

Intrinsic PEEP $=$ static intrinsic positive end-expiratory pressure

volume against flow and identified the inflection point of the curve, defined as the point of maximum slope following the expiratory peak flow. We then subdivided the expired volume from the inflection point to the end of expiration into 5 equal slices (Fig. 1). The slope of the linear fit to flow-volume data for a given volume slice was taken as the time constant for that slice. By plotting tracheal pressure against the corresponding volume above passive functional residual capacity we constructed the tracheal pressure-volume curve. For a given volume slice, the dynamic effective deflation compliance of the respiratory system $\left(\mathrm{C}_{\mathrm{RS}}\right)$, defined as the slope of the tracheal pressurevolume relationship, was determined via linear regression analysis of the deflation tracheal pressure-volume curve on points at that particular volume slice. We calculated total expiratory resistance as time constant/effective deflation $\mathrm{C}_{\mathrm{RS}}$, for each volume slice. We described the tracheal pressure-volume curve with the sigmoidal equation proposed by Venegas et al. ${ }^{8}$ Because the effective deflation $\mathrm{C}_{\mathrm{RS}}$ was nearly constant in each volume slice, we performed linear regression analysis on points obtained via the sigmoidal equation, and determined the effective deflation $\mathrm{C}_{\mathrm{RS}}$ of the volume slice as the slope of the tracheal pressure-volume relationship.

A volume slice was considered non-flow-limited if the expiratory flow was consistently higher when airway pressure was lowered. In a non-flow-limited slice the time constant of the pure respiratory system was calculated as the product of the effective deflation $\mathrm{C}_{\mathrm{RS}}$ and the expiratory $R_{R S}$. The expiratory $R_{R S}$ was calculated by subtract- 


\section{Effect of Albuterol on Expiratory Resistance in Mechanically Ventilated Patients}

Table 3. End-Inspiratory Resistance Before and After Salbutamol

\begin{tabular}{lccc}
\hline \hline & $\begin{array}{c}\text { Before } \\
\text { Salbutamol } \\
\left(\mathrm{cm} \mathrm{H} \mathrm{H}_{2} \mathrm{O} / \mathrm{L} / \mathrm{s}\right)\end{array}$ & $\begin{array}{c}\text { After } \\
\text { Salbutamol } \\
\left(\mathrm{cm} \mathrm{H} \mathrm{H}_{2} \mathrm{O} / \mathrm{L} / \mathrm{s}\right)\end{array}$ & $P$ \\
\hline Maximum & $19.2 \pm 5.3$ & $17.0 \pm 4.7$ & .04 \\
Minimum & $14.6 \pm 4.6$ & $13.0 \pm 4.9$ & .08 \\
Difference & $4.6 \pm 1.8$ & $4.0 \pm 1.8$ & .13 \\
\hline 土values are mean \pm SD. & & & \\
\hline
\end{tabular}

ing the resistance of the endotracheal tube and the expiratory ventilator circuit from the total expiratory resistance. Where flow limitation was present, the time constant obtained from the slope of the flow-volume relationship and total expiratory resistance calculated from the time constant/effective deflation $\mathrm{C}_{\mathrm{RS}}$ ratio were considered to be the time constant of the pure respiratory system and expiratory $R_{R S}$, respectively. We calculated the mean time constant of the pure respiratory system and expiratory $R_{R S}$ by averaging the values of all the volume slices, before and after albuterol administration. We calculated the volume of gas trapped at the end of expiration by subtracting the tidal volume from the exhaled volume measured in step 2 .

\section{Statistical Analysis}

Data were tested for normal distribution with the Shapiro-Wilk W test and analyzed via multi-factors analysis of variance for repeated measurements, followed by the Tukey test for multiple comparisons if the $\mathrm{F}$ value was significant. A $P$ value less than .05 was considered statistically significant. All values are expressed as mean $\pm \mathrm{SD}$.

\section{Results}

Table 1 shows the baseline characteristics of the $10 \mathrm{sub}$ jects. The analyzed volume slice did not differ before and after bronchodilation (mean $\pm \mathrm{SD} 84 \pm 21 \mathrm{~mL}$ vs $84 \pm 22 \mathrm{~mL}$, respectively). In each volume slice both the tracheal pressure-volume and the flow-volume relationships were described with excellent accuracy by linear regression analysis $\left(\mathrm{R}^{2}>0.99\right.$ and $>0.93$, respectively), indicating that in this small portion of volume the pattern of lung emptying may be accurately described by a monoexponential function.

After albuterol the static end-inspiratory airway plateau pressure, intrinsic PEEP, volume trapped at the end of expiration, and end-inspiratory airway resistance (minimum inspiratory $\mathrm{R}_{\mathrm{RS}}$ and maximum inspiratory $\mathrm{R}_{\mathrm{RS}}$ ) significantly decreased (Tables 2 and 3). After albuterol the mean time constant of the pure respiratory system and the mean expiratory $\mathrm{R}_{\mathrm{RS}}$ also significantly decreased $\left(2.51 \pm 1.2 \mathrm{~s}\right.$ vs $2.21 \pm 1.2 \mathrm{~s}$, and $42.68 \pm 17.8 \mathrm{~cm} \mathrm{H}_{2} \mathrm{O} /$ $\mathrm{L} / \mathrm{s}$ vs $38.1 \pm 16.1 \mathrm{~cm} \mathrm{H} \mathrm{O} / \mathrm{L} / \mathrm{s})$. Both before and after albuterol, expiratory $\mathrm{R}_{\mathrm{RS}}$ was significantly higher than inspiratory resistance, and the difference increased considerably toward the end of expiration (see Tables 3 and 4). Independent of the volume slice examined, there was no relationship between albuterol-induced changes in expiratory $\mathrm{R}_{\mathrm{RS}}$ and end-inspiratory airway resistance. Although there was a linear relationship between albuterol-induced changes in time constant and expiratory $\mathrm{R}_{\mathrm{RS}}$, only in the

Table 4. Effects of Salbutamol on Time Constant, Total Resistance, and Resistance of the Respiratory System in Consecutive Volume Slices

\begin{tabular}{|c|c|c|c|c|c|c|c|c|}
\hline \multirow[b]{2}{*}{ Slice } & \multicolumn{2}{|c|}{ Time Constant } & \multicolumn{2}{|c|}{$\begin{array}{l}\text { Time Constant of the } \\
\text { Respiratory System }\end{array}$} & \multicolumn{2}{|c|}{ Total Resistance } & \multicolumn{2}{|c|}{$\begin{array}{l}\text { Expiratory Resistance of the } \\
\text { Respiratory System }\end{array}$} \\
\hline & $\begin{array}{c}\text { Before } \\
\text { Salbutamol } \\
\text { (s) }\end{array}$ & $\begin{array}{c}\text { After } \\
\text { Salbutamol } \\
\text { (s) }\end{array}$ & $\begin{array}{c}\text { Before } \\
\text { Salbutamol } \\
\text { (s) }\end{array}$ & $\begin{array}{c}\text { After } \\
\text { Salbutamol } \\
\text { (s) }\end{array}$ & $\begin{array}{c}\text { Before } \\
\text { Salbutamol } \\
\left(\mathrm{cm} \mathrm{H} \mathrm{H}_{2} \mathrm{O} / \mathrm{L} / \mathrm{s}\right)\end{array}$ & $\begin{array}{c}\text { After } \\
\text { Salbutamol } \\
\left(\mathrm{cm} \mathrm{H} \mathrm{H}_{2} \mathrm{O} / \mathrm{L} / \mathrm{s}\right)\end{array}$ & $\begin{array}{c}\text { Before } \\
\text { Salbutamol } \\
\left(\mathrm{cm} \mathrm{H} \mathrm{H}_{2} \mathrm{O} / \mathrm{L} / \mathrm{s}\right)\end{array}$ & $\begin{array}{c}\text { After } \\
\text { Salbutamol } \\
\left(\mathrm{cm} \mathrm{H} \mathrm{H}_{2} \mathrm{O} / \mathrm{L} / \mathrm{s}\right)\end{array}$ \\
\hline 1 & $\begin{array}{l}1.17 \pm 0.6 \\
P<.001^{*}\end{array}$ & $\begin{array}{l}1.03 \pm 0.5 \\
P<.001^{*}\end{array}$ & $\begin{array}{l}1.09 \pm 0.6 \\
P<.001^{*}\end{array}$ & $\begin{array}{l}0.92 \pm 0.6 \\
P<.001^{*}\end{array}$ & $\begin{array}{c}27.83 \pm 7.5 \\
P<.001 *\end{array}$ & $\begin{array}{r}27.64 \pm 9.3 \\
P<.001^{*}\end{array}$ & $\begin{array}{r}25.92 \pm 8.9 \\
P<.001^{*}\end{array}$ & $\begin{array}{c}22.85 \pm 8.9 \\
P<.001^{*}\end{array}$ \\
\hline 2 & $\begin{array}{l}1.82 \pm 0.7 \\
P=.001^{*}\end{array}$ & $\begin{array}{l}1.66 \pm 1.0 \\
P=.001^{*}\end{array}$ & $\begin{array}{l}1.76 \pm 0.8 \\
P<.001^{*}\end{array}$ & $\begin{array}{l}1.55 \pm 1.0 \\
P=.001^{*}\end{array}$ & $\begin{array}{c}38.41 \pm 14.1 \\
P=.01^{*}\end{array}$ & $\begin{array}{c}40.49 \pm 16.4 \\
P=.03^{*}\end{array}$ & $\begin{array}{c}37.31 \pm 15.9 \\
P=.01^{*}\end{array}$ & $\begin{array}{c}37.40 \pm 16.8 \\
P=.04 *\end{array}$ \\
\hline 3 & $\begin{array}{l}2.38 \pm 1.1 \\
P=.001^{*}\end{array}$ & $\begin{array}{l}2.35 \pm 1.2 \\
P=.001^{*}\end{array}$ & $\begin{array}{l}2.33 \pm 1.1 \\
P=.001^{*}\end{array}$ & $\begin{array}{l}2.27 \pm 1.3 \\
P=.001^{*}\end{array}$ & $\begin{array}{c}41.37 \pm 16.67 \\
P=.01^{*}\end{array}$ & $\begin{array}{c}41.16 \pm 17.1 \\
P=.03^{*}\end{array}$ & $\begin{array}{c}40.43 \pm 18.1 \\
P=.009^{*}\end{array}$ & $\begin{array}{c}37.94 \pm 17.4 \\
P=.02^{*}\end{array}$ \\
\hline 4 & $\begin{array}{l}3.31 \pm 1.6 \\
P=.01^{*}\end{array}$ & $\begin{array}{c}2.82 \pm 1.5 \\
P=.004^{*} \\
P=.02 \dagger\end{array}$ & $\begin{array}{l}3.27 \pm 1.7 \\
P=.01^{*}\end{array}$ & $\begin{array}{l}2.75 \pm 1.6 \\
P=.004 * \\
P=.003 \dagger\end{array}$ & $\begin{array}{c}51.47 \pm 25.1 \\
P=.04 *\end{array}$ & $\begin{array}{c}44.20 \pm 22.0 \\
P=.05^{*} \\
P=.02 \dagger\end{array}$ & $\begin{array}{c}50.81 \pm 26.0 \\
P=.04^{*}\end{array}$ & $\begin{array}{c}43.89 \pm 22.2 \\
P=.05^{*} \\
P=.03 \dagger\end{array}$ \\
\hline 5 & $4.10 \pm 2.1$ & $\begin{array}{l}3.60 \pm 1.8 \\
P=.02 \dagger\end{array}$ & $4.08 \pm 2.1$ & $\begin{array}{l}3.55 \pm 1.9 \\
P=0.02 \dagger\end{array}$ & $59.16 \pm 27.2$ & $\begin{array}{c}51.57 \pm 25.3 \\
P=.04 \dagger\end{array}$ & $58.92 \pm 27.5$ & $\begin{array}{c}52.20 \pm 25.64 \\
P=.04 \dagger\end{array}$ \\
\hline
\end{tabular}

\footnotetext{
\pm values are mean \pm SD.

* Significantly different from the corresponding value at the fifth volume slice (end of expiration).

$\dagger$ Significantly different from the corresponding value (for a given volume slice) before salbutamol.
} 


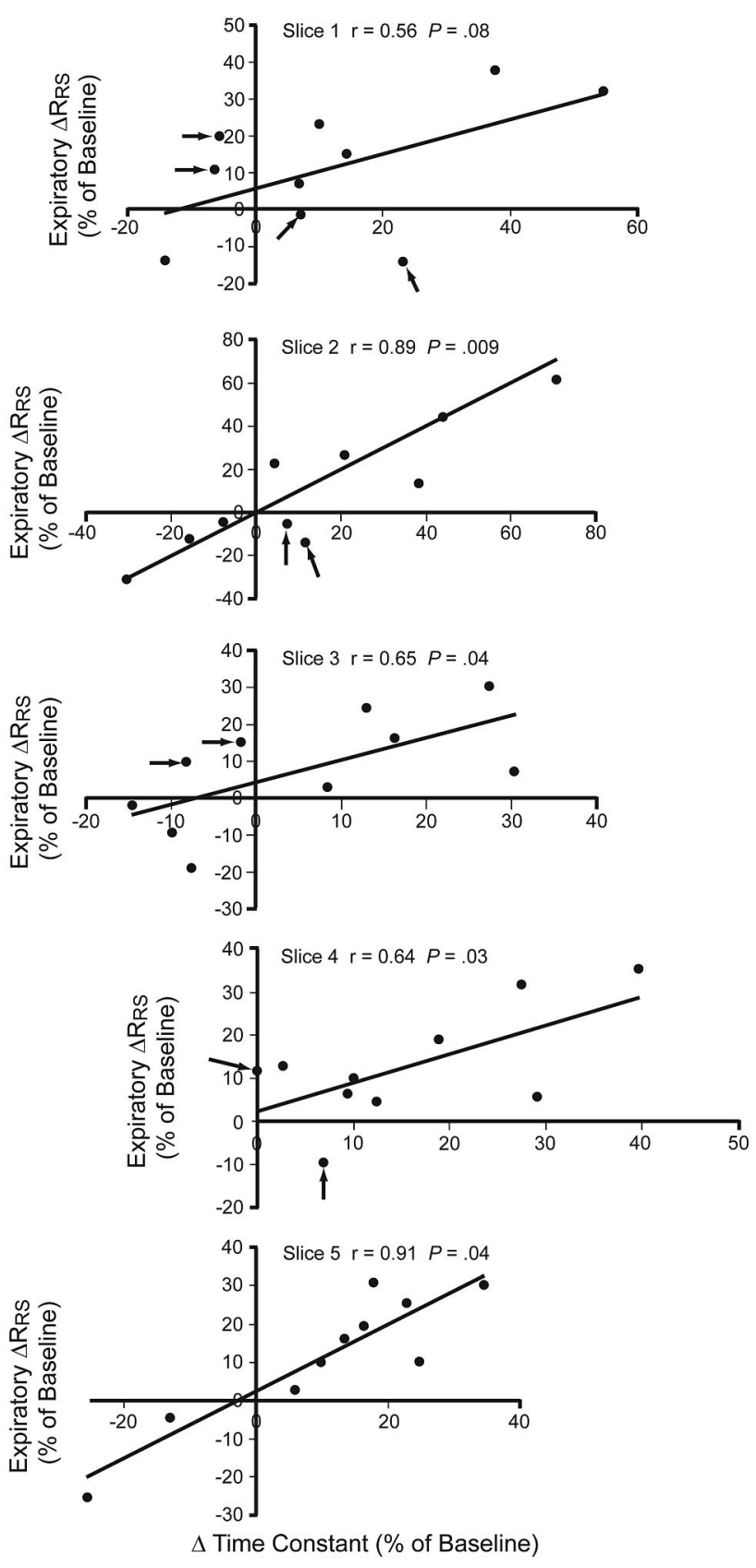

Fig. 2. Relationship between albuterol-induced changes in the time constant of the total system (respiratory system, endotracheal tube, ventilator circuit, the change in the time constant, and the expiratory resistance of the respiratory system $\left(\Delta \mathrm{R}_{\mathrm{RS}}\right)$ at each volume slice. The arrows indicate patients in whom the albuterol-induced change in the change in the time constant was in the opposite direction of $\Delta \mathrm{R}_{\mathrm{RS}}$.

last volume slice did the response of time constant accurately reflect the corresponding changes in expiratory $R_{R S}$ (Fig. 2). In all but the last volume slice, albuterol-induced change in the time constant was in the opposite direction of the inspiratory $\Delta \mathrm{R}_{\mathrm{RS}}$, in at least 2 of the 10 patients.
Table 5. Expiratory Compliance of the Respiratory System

\begin{tabular}{lcc}
\hline \hline Slice & $\begin{array}{c}\text { Before Salbutamol } \\
(\text { mean } \pm \text { SD) }\end{array}$ & $\begin{array}{c}\text { After Salbutamol } \\
(\text { mean } \pm \text { SD) }\end{array}$ \\
\hline 1 & $0.041 \pm 0.01$ & $0.040 \pm 0.01$ \\
& $P<.001^{*}$ & $P=.001^{*}$ \\
2 & $0.049 \pm 0.01$ & $0.044 \pm 0.01$ \\
& $P=.002^{*}$ & $P=.006^{*}$ \\
3 & $0.057 \pm 0.01$ & $0.058 \pm 0.01$ \\
& $P=.004^{*}$ & $P=.03^{*}$ \\
4 & $0.063 \pm 0.01$ & $0.061 \pm 0.01$ \\
& $P=.006^{*}$ & $P=.02^{*}$ \\
5 & $0.068 \pm 0.02$ & $0.067 \pm 0.02$ \\
& & \\
* Significantly different from the corresponding value at the fifth volume slice (end of \\
expiration).
\end{tabular}

Both with and without albuterol, the effective deflation $\mathrm{C}_{\mathrm{RS}}$, time constant, and time constant of the pure respiratory system increased significantly from the beginning (first slice) to the end of expiration (fifth slice) (see Tables 4 and 5). After albuterol the time constant and time constant of the pure respiratory system in the 4th and 5th slices significantly decreased, compared to before albuterol. These changes in time constant were entirely due to alterations in expiratory $R_{R S}$, since effective deflation $C_{R S}$ was not affected by albuterol (see Table 5).

\section{Discussion}

Our main findings are:

- In mechanically ventilated patients with COPD exacerbation, inhaled albuterol significantly decreased the expiratory resistance and increased the rate of lung emptying at the end of expiration.

- Expiratory resistance was several-fold higher than endinspiratory airway resistance.

- There was no correlation between albuterol-induced changes in expiratory and inspiratory resistance.

- Albuterol-induced changes in the flow-volume relationship (ie, time constant) fairly accurately predicted the corresponding changes in expiratory resistance only at the end of expiration.

To our knowledge this is the first study that has quantified the effect of bronchodilators on expiratory resistance in mechanically ventilated patients. Previous studies have indirectly examined the effect of bronchodilators on expiratory resistance, mainly by measuring flow at similar recoil pressure: a technique that does not take account of the presence of flow limitation or the nonlinearity of the quasistatic pressure-volume relationships during expiration..$^{9,10}$ We considered both factors and found that albuterol de- 
creased expiratory resistance and the time constant of the respiratory system by approximately $10 \%$ and $15 \%$, respectively. Our assessment of flow limitation was performed with a simple and well validated method proposed by Gottfried et al. ${ }^{11}$ The forced oscillation technique is also applicable in paralyzed mechanically ventilated patients, ${ }^{12}$ but technical difficulties and the need for specific equipment limit the use of that method.

Since calculation of expiratory resistance is rather complex and not currently easily conducted at the bedside, it would be of interest to examine whether the bronchodilator response of inspiratory resistance, obtained easily via the end-inspiratory occlusion method, predicts the corresponding changes in expiratory resistance. As expected, albuterol decreased the minimum and maximum end-inspiratory $R_{R S}$ ) in mechanically ventilated patients with COPD exacerbation, in agreement with previous studies. ${ }^{2,4,13}$ Nonetheless, both with and without albuterol, expiratory resistance at the beginning of expiration was approximately $85 \%$ higher than end-inspiratory resistance, and increased more than 3-fold toward the end of expiration. Albuterol-induced decrease in expiratory resistance was greater toward the end of expiration. Importantly, there was no relationship between the albuterol-induced changes in end-inspiratory resistance and expiratory resistance. These results indicate that the determinants of the resistance, as well as of the bronchodilator response, are different between inspiration and expiration. Flow limitation and airway compression during expiration probably account for that difference, so the drug-induced changes in inspiratory resistance cannot be used as an index of the corresponding response of expiratory resistance.

Additionally, we tested the hypothesis that bronchodilator-induced change of the time constant of the whole system, as indicated by the expiratory flow-volume curve screen, could accurately predict changes in expiratory resistance. We calculated the expiratory time constant via regression analysis, using independent small-volume (approximately $85 \mathrm{~mL}$ ) slices, which is a method that largely circumvents the problem of the shape of the flow-volume curve in patients with COPD. In this relatively small volume range, the flow-volume and pressure-volume relationships were highly linear, with an $r$ value approaching unity in all cases. Therefore, it is reasonable to assume that in these patients each volume slice can be characterized by a single value of compliance and resistance.

Our data indicate that albuterol-induced changes in the expiratory flow-volume relationship do not accurately reflect corresponding changes in expiratory resistance, except in the last volume slice. This might be because albuterol reversed the flow limitation, particularly at early expiration. We previously found that the time constant of the whole system and that of the respiratory system are similar in the presence- but not in the absence- of flow limitation, ${ }^{6,7}$ so at zero PEEP only the bronchodilator response of the flow-volume relationship at the end of expiration can be used to quantify the corresponding response of expiratory resistance. We did not evaluate the effect of PEEP on the bronchodilator response, although applied PEEP may be beneficial during controlled mechanical ventilation in some patients. Nonetheless, it has not been clearly determined in which patients applied PEEP improves lung emptying, or the optimum PEEP for each patient. $^{14}$

\section{Conclusions}

In mechanically ventilated COPD-exacerbation patients, inhaled albuterol significantly decreased expiratory resistance and increased the rate of lung emptying. The albuterol-induced changes in expiratory resistance did not correlate with the changes in end-inspiratory resistance. Furthermore, only at the end of expiration did albuterolinduced changes in the flow-volume relationship (ie, the time constant) predict corresponding changes in expiratory resistance. Thus, neither the inspiratory resistance nor the whole expiratory flow-volume curve can be used to evaluate bronchodilator response of expiratory resistance. This is an important consideration both for evaluating bronchodilator response in the ICU and for studying bronchodilator's effect in obstructive lung diseases. ${ }^{15}$ Among the limitations of this method are the need for deep sedation and possibly muscle relaxation, and the complicated calculations required to measure expiratory resistance. Yet, future development of appropriate ventilator software could simplify this procedure and provide measurements of expiratory resistance on the ventilator screen.

\section{REFERENCES}

1. Siafakas NM, Vermeire P, Pride NB, Paoletti P, Gibson J, Howard $\mathrm{P}$, et al. Optimal assessment and management of chronic obstructive pulmonary disease (COPD). The European Respiratory Society Task Force. Eur Respir J 1995;8(8):1398-1420.

2. Dhand R, Jubran A, Tobin MJ. Bronchodilator delivery by metereddose inhaler in ventilator-supported patients. Am J Respir Crit Care Med 1995;151(6):1827-1833.

3. Manthous CA, Hall JB, Schmidt GA, Wood LD. Metered-dose inhaler versus nebulized albuterol in mechanically ventilated patients. Am Rev Respir Dis 148(6 Pt 1):1993, 1567-1570.

4. Mouloudi E, Katsanoulas K, Anastasaki M, Askitopoulou E, Georgopoulos D. Bronchodilator delivery by metered-dose inhaler in mechanically ventilated COPD patients: influence of end-inspiratory pause. Eur Respir J 1998;12(1):165-169.

5. D'Angelo E, Robatto FM, Calderini E, Tavola M, Bono D, Torri G, et al. Pulmonary and chest wall mechanics in anesthetized paralyzed humans. J Appl Physiol 1991;70(6):2602-2610.

6. Kondili E, Alexopoulou C, Prinianakis G, Xirouchaki N, Georgopoulos D. Pattern of lung emptying and expiratory resistance in mechanically ventilated patients with chronic obstructive pulmonary disease. Intensive Care Med 2004;30(7):1311-1318. 


\section{Effect of Albuterol on Expiratory Resistance in Mechanically Ventilated Patients}

7. Kondili E, Prinianakis G, Athanasakis H, Georgopoulos D. Lung emptying in patients with acute respiratory distress syndrome: effects of positive end-expiratory pressure. Eur Respir J 2002;19(5):811-819.

8. Venegas JG, Harris RS, Simon BA. A comprehensive equation for the pulmonary pressure-volume curve. J Appl Physiol 1998;84(1):389-395.

9. Gay PC, Patel HG, Nelson SB, Gilles B, Hubmayr RD. Metered dose inhalers for bronchodilator delivery in intubated, mechanically ventilated patients. Chest 1991;99(1):66-71.

10. Gay PC, Rodarte JR, Tayyab M, Hubmayr RD. Evaluation of bronchodilator responsiveness in mechanically ventilated patients. Am Rev Respir Dis 1987;136(4):880-885.

11. Gottfried SB, Rossi A, Higgs BD, Calverley PM, Zocchi L, Bozic C, et al. Noninvasive determination of respiratory system mechanics during mechanical ventilation for acute respiratory failure. Am Rev Respir Dis 1985;131(3):414-420.
12. Navajas D, Farre R. Forced oscillation assessment of respiratory mechanics in ventilated patients. Crit Care 2001;5(1):3-9.

13. Mouloudi E, Katsanoulas K, Anastasaki M, Hoing S, Georgopoulos D. Bronchodilator delivery by metered-dose inhaler in mechanically ventilated COPD patients: influence of tidal volume. Intensive Care Med 1999;25(11):1215-1221.

14. Caramez MP, Borges JB, Tucci MR, Okamoto VN, Carvalho CR, Kacmarek RM, et al. Paradoxical responses to positive end-expiratory pressure in patients with airway obstruction during controlled ventilation. Crit Care Med 2005;33(7):1519-1528.

15. Levin DL, Garg A, Hall LJ, Slogic S, Jarvis JD, Leiter JC. A prospective randomized controlled blinded study of three bronchodilators in infants with respiratory syncytial virus bronchiolitis on mechanical ventilation. Pediatr Crit Care Med 2008;9(6): 598-604. 